\title{
The short term burden of ambient gaseous air pollution on chronic obstructive pulmonary disease in Pudong New Area, China: A time-stratified case- crossover study with a distributed lag nonlinear model
}

\section{Yichen Chen}

Shanghai Pudong New Area Center for Disease Control and Prevention, Fudan University Pudong Institute of Preventive Medicine

\section{Xiaopan Li}

Shanghai Pudong New Area Center for Disease Control and Prevention, Fudan University Pudong Institute of Preventive Medicine

\section{Hanyi Chen}

Shanghai Pudong New Area Center for Disease Control and Prevention, Fudan University Pudong Institute of Preventive Medicine

\section{Lianghong Sun}

Shanghai Pudong New Area Center for Disease Control and Prevention, Fudan University Pudong Institute of Preventive Medicine

\section{Tao Lin}

Shanghai Pudong New Area Center for Disease Control and Prevention, Fudan University Pudong Institute of Preventive Medicine

\section{Shaotan Xiao}

Shanghai Pudong New Area Center for Disease Control and Prevention, Fudan University Pudong Institute of Preventive Medicine

\section{Minjuan Yang}

Shanghai Pudong New Area Center for Disease Control and Prevention, Fudan University Pudong Institute of Preventive Medicine

\section{Genming Zhao}

Fudan University

\section{Li Peng ( $\square$ phyllis_pl@163.com)}

Shanghai Key Laboratory of Meteorology and Health

\section{Yi Zhou ( $D$ yizhou517@163.com )}

Shanghai Pudong New Area Center for Disease Control and Prevention, Fudan University Pudong Institute of Preventive Medicine 


\section{Research Article}

Keywords: Air pollution, Chronic obstructive pulmonary disease, Years of life lost, Mortality

Posted Date: December 15th, 2020

DOl: https://doi.org/10.21203/rs.3.rs-109352/v1

License: (c) (i) This work is licensed under a Creative Commons Attribution 4.0 International License. Read Full License 
The short term burden of ambient gaseous air pollution on chronic obstructive pulmonary disease in Pudong New Area, China: A time-stratified case-crossover study with a distributed lag nonlinear model

Yichen Chen ${ }^{1} \dagger$, Xiaopan $\mathrm{Li}^{1,2} \dagger$, Hanyi Chen ${ }^{1}$, Lianghong Sun ${ }^{1}$, Tao Lin ${ }^{1}$, Shaotan Xiao' ${ }^{1}$, Minjuan Yang ${ }^{1}$, Genming Zhao ${ }^{2}$, Li Peng ${ }^{3 *}$ and Yi Zhou ${ }^{1 *}$

1. Shanghai Pudong New Area Center for Disease Control and Prevention, Fudan University Pudong Institute of Preventive Medicine, Pudong New Area, Shanghai, China 200136, P. R. China.

2. School of Public Health, Fudan University, Shanghai 200032, China.

3. Shanghai Key Laboratory of Meteorology and Health, Xuhui District, Shanghai, China 200030, P. R. China.

*For correspondence: Yi Zhou, Shanghai Pudong New Area Center for Disease Control and Prevention, 3039 Zhangyang Rd., Shanghai 200136, P. R. China. E-mail: yizhou517@163.com. Tel: +86-21-50342482; Li Peng, Shanghai Meteorological Service, 166 Puxi Rd., Shanghai 200030, P. R. China. E-mail: phyllis_pl@163.com. Tel: +86-21-54896000

† Yichen Chen and Xiaopan Li contributed equally to this work.

\section{E-mail addresses for all authors}

Yichen Chen, E-mail: ycchen0907@139.com

Xiaopan Li, E-mail: xiaopanli0224@126.com

Hanyi Chen, E-mail:seachy@sina.com

Lianghong Sun, E-mail: Ihsun@pdcdc.sh.cn

Tao Lin, E-mail: tlin@pdcdc.sh.cn

Shaotan Xiao, E-mail: stxiao@pdcdc.sh.cn

Minjuan Yang, E-mail: mjyang@pdcdc.sh.cn

Genming Zhao, E-mail: gmzhao@shmu.edu.cn

Li Peng, E-mail: phyllis_pl@163.com 
Yi zhou, E-mail: yizhou517@163.com

Word counts: Main manuscript, 6423; Abstract, 300; Tables, 5; Figures, 1; Reference, 44; Additional file, 1.

\section{Abstract}

Background: Air pollution is a severe and dangerous public health problem. However, the effect of ambient gaseous air pollution exposure on years of life lost (YLL) attributable to chronic obstructive pulmonary disease (COPD) mortality has not been quantitatively verified.

Methods: We collected the data of 12,781 COPD deaths and ambient gaseous air pollutants, including sulfur dioxide $\left(\mathrm{SO}_{2}\right)$, nitrogen dioxide $\left(\mathrm{NO}_{2}\right)$, Carbon monoxide $(\mathrm{CO})$, and ozone $\left(\mathrm{O}_{3}\right)$, during the years 2013-2019 in the Shanghai Pudong New Area (PNA). Then we performed a time-stratified case-crossover study combined with a distributed lag nonlinear model (DLNM) to estimate the impact of those air pollutants on daily COPD deaths counts and YLL. The confounders including long-term trend and meteorological factors have been controlled for, and effects of age and educational attainment as effect modifiers have also been evaluated.

Results: During the 2013-2019 time frame, increases of $10 \mu \mathrm{g} / \mathrm{m}^{3}$ in $\mathrm{SO}_{2}$ and $\mathrm{NO}_{2}$ were associated with a $4.93 \%(95 \% \mathrm{Cl}: 1.47 \%, 8.50 \%)$ and $1.47 \%(95 \%$ $\mathrm{Cl}: 0.14 \%, 2.82 \%)$ in daily COPD death counts at lag0-1day, respectively, a 2.52 (95\% Cl: $0.31,4.72)$ YLL increase and $0.85(95 \% \mathrm{Cl}: 0.01,1.68)$ YLL increase at lag0-1day, respectively. A $1 \mathrm{mg} / \mathrm{m}^{3}$ increase in $\mathrm{CO}$ was associated 
with a $9.46 \%(95 \% \mathrm{Cl}: 0.40 \%, 19.35 \%)$ at lag0 increase in daily COPD death counts. No significant impact from $\mathrm{O}_{3}$ on both daily COPD deaths counts and YLL $(P>0.05)$. The impact of gaseous air pollutants on the daily COPD death count and YLL were significant in populations of older adults and the lower educated population, while an insignificant effect was observed in the younger population and higher educated population. The YLL due to COPD related to $\mathrm{SO}_{2}$ and $\mathrm{CO}$ for the lower educated population was significantly higher than those for the higher educated population.

Conclusion: Reducing specific gaseous air pollutants will help to control COPD deaths and improve the population's life expectancy.

Key words: Air pollution, Chronic obstructive pulmonary disease, Years of life lost, Mortality

\section{Introduction}

Due to the process of rapid industrialization and urbanization as well as the increase of motorized traffic, air pollution has become a serious issue in China that has gained widespread concern around the world [1-3]. Numerous epidemiological studies have proved the relation between the short-term exposure to ambient air pollution and a variety of causes of death, including respiratory diseases [4-6], cardiovascular disease $[7,8]$ and non-accidental mortality [9-11]. Most of these studies were focus on particulate matter (PM) or the pollutants originating from the combustion of fossil fuels including sulfur 
dioxide $\left(\mathrm{SO}_{2}\right)$ and nitrogen dioxide $\left(\mathrm{NO}_{2}\right)$, however, the effect of ozone $\left(\mathrm{O}_{3}\right)$ and carbon monoxide (CO) on excess deaths was rarely considered. Furthermore, most of these studies only use the daily death count as the dependent variable, which may ignore the influence of the person's age at death and can lead to an overestimation.

Years of life lost (YLL) could effectively assess the death burden by taking the life expectancy at death into consideration [12]. Higher weights would be assigned to a death that occurs at younger ages, thus YLL is more precise than daily death count in the assessment of excess mortality and premature death [13]. From the perspective of public health, the assessment of the relationship between air pollution and YLL has an important significance and could provide further information in its policy formulation.

Chronic obstructive pulmonary disease (COPD) is a group of chronic respiratory diseases that are characterized by irreversible airflow obstruction [14]. According to WHO statistics, COPD was the fifth leading cause of mortality worldwide in 2011. By 2030, it is expected to be the third leading cause of death [15]. The global disease burden study showed that COPD was the ninth leading cause of death contributing to global YLL in 2016 [16]. A number of former studies have proven the association between the short-term exposure to ambient gaseous air pollution and the daily death count from COPD $[4,6,17]$. However, studies exploring the association between ambient gaseous air pollution and YLL due to COPD are still rare. Furthermore, the 
effects of socioeconomic factors including age and education attainment were unclear up to now.

Pudong New Area (PNA), a microcosm of urbanization in China, accounts for one-fifth of the total population in Shanghai. PNA, consisting of both urbanized and rural places, is also suffering from a serious air pollution problem and home to an increasing aged population. Improving the health of elderly patients, who account for the majority of COPD patients, meets the core requirements of "Healthy China 2030". The plan is to improve life expectancy and reduce the premature mortality caused by four main non-communicable diseases of residents [18, 19].

In this study, we conducted a time-stratified case-crossover design with a distributed lag non-linear model (DLNM) to assess the association between the short-term exposure to ambient gaseous air pollution $\left(\mathrm{SO}_{2}, \mathrm{NO}_{2}, \mathrm{CO}, \mathrm{O}_{3}\right)$ and the disease burden of COPD in PNA, during the years 2013-2019, to provide a reference for controlling air pollution and building a healthy aging population.

\section{Materials and Methods}

\section{Air pollution and meteorological data}

We collected the 24 hour mean concentrations of inhalable particulate matter $(\mathrm{PM} 10)$, sulfur dioxide $\left(\mathrm{SO}_{2}\right)$, nitrogen dioxide $\left(\mathrm{NO}_{2}\right)$, carbon monoxide (CO) and the maximum 8 hour average ozone $\left(\mathrm{O}_{3}\right)$ from the Shanghai 
Environmental Monitoring Center. These values were obtained from nine comprehensive monitoring stations in Shanghai during the course of the years 2013-2019. Due to the vast geographical range of PNA, the data derived from the three conventional monitoring stations located in the district were insufficient to cover the whole study area. Thus, we collected the meteorological information from six other nearby monitoring stations as supplementary data to safeguard the reliability and integrality of the overall data.

The meteorological data collected includes the mean, minimum, and maximum temperature $\left({ }^{\circ} \mathrm{C}\right)$, relative humidity $(\%)$ and the atmospheric pressure $(\mathrm{hPa})$ from the Shanghai Key Laboratory of Meteorology and Health. All the weather data was obtained from the automatic monitoring station located at Century Park in PNA.

Mortality and YLL data

Daily mortality data of the residents in PNA during the years 2013-2019 were derived from the vital statistic database. Using the Mortality Registration System of PNA, including the medical institutions of all levels and the local civil administration department, the mortality data was checked monthly against the local population registry. The personnel of Pudong New Area Center for Disease Control and Prevention (PDCDC) performed periodic assessment and data cleaning according to standard guidelines, and the funeral system has been fully implemented since the 1980s. By taking all of 
these measures together, the completeness of the death registration system had been improved to the maximum extent.

The cause of death was coded, according to the International Classification of Diseases 10th version (ICD-10), and the deaths from COPD (ICD-10: J40-J47) were classified by the underlying cause. The direct and underlying causes of death were coded by qualified staff, and all of these records were further examined and verified by the PDCDC. If any ill-defined records were found, the trained investigator would review the medical records, investigate with the family members, or consult the police records, thus guaranteeing the integrity and accuracy of the data.

After matching the age and sex, we calculated the YLL values for each COPD death, then, summed these up to yield the daily YLL from COPD. Both the death counts and YLL from COPD, stratified by age (<80years and $\geq 80 y e a r s$ ) and education attainment (illiteracy or elementary school education and over middle school education), were used as the analysis indicators.

\section{Statistic analysis}

The descriptive statistics, including mean value, standard deviation, median, quartile, and Spearman correlation, were used to test the correlation among variables.

We performed a time-stratified case-crossover study combining with the distributed lag nonlinear model (DLNM) based on a conditional Poisson 
regression model to assess the impact of ambient gaseous air pollution $\left(\mathrm{SO}_{2}\right.$, $\mathrm{NO}_{2}, \mathrm{CO}, \mathrm{O}_{3}$ ) on YLL[20-22].

Since the dependent variable of daily YLL fits the normal distribution, Gaussian was used as the family function in a conditional Poisson model.

The model is listed as follows:

$Y L L t=\alpha+\beta T t, I+\mathrm{ns}(t e m p, d f)+\mathrm{ns}(r h, d f)+\mathrm{ns}(p r e, d f)+\gamma S t r a t a t$

In this model, YLLt is the sum of YLL caused by COPD death that happened at day $t . \alpha$ is the intercept. $T t, l$ is the cross-basis object we used to assess the linear effect of gaseous air pollution, where $T$ is the daily mean concentration of the gaseous air pollution at day $t$ including $\mathrm{SO}_{2}, \mathrm{NO}_{2}, \mathrm{CO}, \mathrm{O}_{3}$, and $/$ is the lag days. Referring to previous studies, we set the maximal lag up to 7 days to explore the lag pattern of gaseous air pollution. $\beta$ is the coefficient for $T t, l$ associated with a $1 \mu \mathrm{g}$ increase in $\mathrm{SO}_{2}, \mathrm{NO}_{2}, \mathrm{O}_{3}$, and a $1 \mathrm{mg}$ increase in CO. Factor ns is the natural cubic spline function to control the nonlinear-relationships between YLL and meteorological factors. The temp is the daily mean temperature $\left({ }^{\circ} \mathrm{C}\right) ; r h$ is the daily average relative humidity $(\%)$; pre is the daily average air pressure; $d f$ is the degree of freedom, in accordance with the study performed before, we set the values of $d f$ at 5,3 and 3 for these meteorological factors, respectively[23, 24]. Stratat is the time stratum to control for trend and season in the time-stratified case-crossover study, and $\gamma$ is the coefficients for time stratum. The results were presented by 
the changes of daily YLL with a $10 \mu \mathrm{g}$ increase in $\mathrm{SO}_{2}, \mathrm{NO}_{2}, \mathrm{O}_{3}$, and a $1 \mathrm{mg}$ increase in $\mathrm{CO}$.

The analyses were also stratified by age and education attainment. We calculated the $95 \%$ confidence intervals $(\mathrm{Cl})$ to test the statistical significance for the difference between the groups with different modifiers.

A single pollutant model was conducted to explore the main association between the gaseous air pollution and daily YLL. The stability of these associations was examined by using multi-pollutants models with other gaseous air pollution and air particulate matter of the same period.

In addition, we evaluated the impacts of gaseous air pollution on daily death counts due to COPD. Using the daily death count as a dependent variable following a Poisson distribution, the family function for a conditional Poisson model was Poisson. The independent variable, lag structure, in the model was similar to those in the YLL model. Relative risk (RR) of mortality and percentage increase of death counts from COPD per a $10 \mu \mathrm{g} / \mathrm{m}^{3}$ increase in $\mathrm{SO}_{2}, \mathrm{NO}_{2}, \mathrm{O}_{3}$, and per a $1 \mathrm{mg} / \mathrm{m}^{3}$ increase in $\mathrm{CO}$ were used to present the results.

In this study, all statistical analyses were conducted with $\mathrm{R}$ software (Version 3.4.2). The dlnm package and gnm package were used to perform the distributed lag nonlinear model (DLNM) and conditional Poisson model, respectively. $p<0.05$ was considered to be statistically significant. The study 
design was in accord with the ethical guidelines of the 1975 Declaration of Helsinki and was also approved by the institutional review board of Shanghai Pudong New Area Center for Disease Control and Prevention.

\section{Results}

The average daily concentrations of $\mathrm{SO}_{2}, \mathrm{NO}_{2}, \mathrm{O}_{3}$ and $\mathrm{CO}$ were $14.4 \mu \mathrm{g} / \mathrm{m}^{3}, 44.2 \mu \mathrm{g} / \mathrm{m}^{3}, 103.0 \mu \mathrm{g} / \mathrm{m}^{3}$ and $0.8 \mathrm{mg} / \mathrm{m}^{3}$, respectively, during the years 2013 to 2019 in PNA, China, shown in Table 1. Correlations between air pollutants and meteorological conditions were examined by a Spearman correlation function and presented in Table 2. Ambient air pollutants and meteorological conditions were correlated with each other, with the most significant correlations observed between the five air pollutants.

We identified a total of 12,781 deaths from COPD during 2013 to 2019 . The mean daily death counts and YLL due to COPD were 5.0 and 52.5 respectively. The average daily death count and YLL for the elderly and lower educated were higher than that of the young and the higher educated, respectively (Table 1).

Table 1: Daily air pollutants, meteorological condition, COPD death counts and YLL in PNA, China, 2013-2019.

\begin{tabular}{lccccccc}
\hline Variables & Mean $\pm \mathrm{SD}$ & Minimum & 25 th & Median & 75th & Maximum & Interquartile range \\
\hline $\mathrm{PM}_{10}\left(\mu \mathrm{g} / \mathrm{m}^{3}\right)$ & $62.2 \pm 39.0$ & 6 & 37 & 52 & 76 & 467 & 39 \\
$\mathrm{SO}_{2}\left(\mu \mathrm{g} / \mathrm{m}^{3}\right)$ & $14.4 \pm 10.4$ & 4 & 9 & 12 & 16 & 103 & 7 \\
$\mathrm{NO}_{2}\left(\mu \mathrm{g} / \mathrm{m}^{3}\right)$ & $44.2 \pm 20.2$ & 6 & 29 & 41 & 55 & 139 & 26 \\
$\mathrm{O}_{3}\left(\mu \mathrm{g} / \mathrm{m}^{3}\right)$ & $103.0 \pm 44.5$ & 11 & 72 & 96 & 126 & 302 & 54
\end{tabular}




\begin{tabular}{|c|c|c|c|c|c|c|c|}
\hline $\mathrm{CO}\left(\mathrm{mg} / \mathrm{m}^{3}\right)$ & $0.8 \pm 0.3$ & 0.3 & 0.6 & 0.7 & 0.9 & 3.0 & 0.30 \\
\hline Temperature $\left({ }^{\circ} \mathrm{C}\right)$ & $17.4 \pm 8.5$ & -5.4 & 10.0 & 18.3 & 24.1 & 34.6 & 14 \\
\hline Relative humidity (\%) & $75.1 \pm 12.5$ & 22.6 & 67.3 & 76.6 & 84.1 & 100.0 & 17 \\
\hline Air pressure (hPa) & $1016 \pm 9.0$ & 989.6 & 1008.4 & 1016.0 & 1023.0 & 1039.3 & 15 \\
\hline \multicolumn{8}{|l|}{ Years of life lost (years) } \\
\hline Total & $52.5 \pm 30.8$ & 0.0 & 30.3 & 48.1 & 69.6 & 199.6 & 39.4 \\
\hline Age $<80$ years & $18.5 \pm 17.8$ & 0.0 & 6.6 & 14.6 & 28.0 & 117.9 & 21.4 \\
\hline Age $\geq 80$ years & $34.0 \pm 22.9$ & 0.0 & 16.9 & 30.2 & 46.4 & 150.2 & 29.5 \\
\hline low educated population & $29.8 \pm 18.4$ & 0.0 & 16.2 & 26.9 & 39.9 & 110.5 & 23.7 \\
\hline well educated population & $22.7 \pm 22.0$ & 0.0 & 0.0 & 16.1 & 34.6 & 133.0 & 34.6 \\
\hline \multicolumn{8}{|l|}{ Daily death counts } \\
\hline Total & $5.0 \pm 2.7$ & 0 & 3 & 5 & 6 & 17 & 3 \\
\hline Age $<80$ years & $1.5 \pm 1.3$ & 0 & 1 & 1 & 2 & 7 & 1 \\
\hline Age $\geq 80$ years & $3.5 \pm 2.2$ & 0 & 2 & 3 & 5 & 15 & 3 \\
\hline low educated population & $3.7 \pm 2.3$ & 0 & 2 & 3 & 5 & 14 & 3 \\
\hline well educated population & $1.3 \pm 1.2$ & 0 & 0 & 1 & 2 & 9 & 2 \\
\hline
\end{tabular}

Note: YLL, year of life lost

Table 2: Spearman correlation between weather conditions and air pollutants in PNA, China, 2013-2019.

\begin{tabular}{|c|c|c|c|c|c|c|c|c|}
\hline & PM10 & $\mathrm{SO} 2$ & $\mathrm{NO} 2$ & $\mathrm{O} 3$ & $\mathrm{CO}$ & $\begin{array}{c}\text { Temperature } \\
\left({ }^{\circ} \mathrm{C}\right)\end{array}$ & $\begin{array}{c}\text { Relative humidity } \\
(\%)\end{array}$ & $\begin{array}{c}\text { Air pressure } \\
(\mathrm{hPa})\end{array}$ \\
\hline PM10 & 1 & - & - & - & - & - & - & - \\
\hline SO2 & $0.72^{\star \star}$ & 1 & - & - & - & - & - & - \\
\hline NO2 & $0.64^{* *}$ & $0.57^{\star *}$ & 1 & - & - & - & - & - \\
\hline O3 & $0.18^{\star *}$ & -0.01 & $-0.20^{* *}$ & 1 & - & - & - & - \\
\hline $\mathrm{CO}$ & $0.71^{* \star}$ & $0.62^{* *}$ & $0.72^{* *}$ & $-0.09^{* *}$ & 1 & - & - & - \\
\hline Temperature $\left({ }^{\circ} \mathrm{C}\right)$ & $-0.26^{\star *}$ & $-0.36^{* *}$ & $-0.48^{\star *}$ & $0.50^{\star *}$ & $-0.29^{* *}$ & 1 & - & - \\
\hline Relative humidity (\%) & $-0.47^{* *}$ & $-0.46^{* *}$ & $-0.16^{* *}$ & $-0.25^{\star *}$ & $-0.09^{* *}$ & $0.24^{\star *}$ & 1 & - \\
\hline Air pressure (hPa) & $0.22^{* \star}$ & $0.34^{* *}$ & $0.41^{* *}$ & $-0.44^{* *}$ & $0.19^{* *}$ & $-0.88^{* *}$ & $-0.35^{\star \star}$ & 1 \\
\hline
\end{tabular}

${ }^{*} P<0.05,{ }^{* *} P<0.01$

The estimated changes with 95\% confidence intervals in YLL and RR of the daily death count from COPD on single-day lag and muti-day lag with 10 $\mu \mathrm{g} / \mathrm{m}^{3}$ increase of $\mathrm{SO}_{2}, \mathrm{NO}_{2}, \mathrm{O}_{3}$, and $1 \mathrm{mg} / \mathrm{m}^{3}$ increase of $\mathrm{CO}$ are presented 
in Figure 1. Since, the single-day lag model could underestimate the relation between air pollution and death, the seven-day cumulative effect of gaseous air pollution on YLL and death counts due to COPD has also been assessed and summarized in Table 3. Generally, the association with $\mathrm{SO}_{2}, \mathrm{NO}_{2}$ and $\mathrm{CO}$ lasted for different periods, and the lag pattern for YLL and RR were similar. The effect of $\mathrm{O}_{3}$ was not significant on the daily COPD death count and YLL, and the impact of $\mathrm{CO}$ was not significant on YLL due to COPD. For the daily death count from COPD, the single pollutant model showed that a $10 \mu \mathrm{g} / \mathrm{m}^{3}$ increase in $\mathrm{SO}_{2}$ and $\mathrm{NO}_{2}$ was associated with a $4.93 \%(95 \% \mathrm{Cl}: 1.47 \%, 8.50 \%)$ and a $1.47 \%(95 \% \mathrm{Cl}: 0.14 \%, 2.82 \%)$ increase in daily COPD death count at lag0-1day. A $1 \mathrm{mg} / \mathrm{m}^{3}$ increase in $\mathrm{CO}$ was associated with a $9.46 \%(95 \% \mathrm{Cl}$ : $0.40 \%, 19.35 \%)$ increase in the daily COPD death count. For YLL, in the single pollutant model, a $10 \mu \mathrm{g} / \mathrm{m}^{3}$ increase in $\mathrm{SO}_{2}$ and $\mathrm{NO}_{2}$ was associated with a $2.52(95 \% \mathrm{Cl}: 0.31,4.72), 0.85(95 \% \mathrm{Cl}: 0.01,1.68)$ increase in YLL due to COPD death at lag0-1day.

Figure 1: The estimated changes with a $95 \%$ confidence interval in daily COPD death counts and YLL associated with $10 \mu \mathrm{g} / \mathrm{m}^{3}$ increase in $\mathrm{SO}_{2}, \mathrm{NO}_{2}$, $\mathrm{O}_{3}$, and $1 \mathrm{mg} / \mathrm{m}^{3}$ increase in $\mathrm{CO}$ in different lag days in PNA, China, 2013-2019. The effects of seasonality, day of the week, and meteorological factors have been adjusted. 

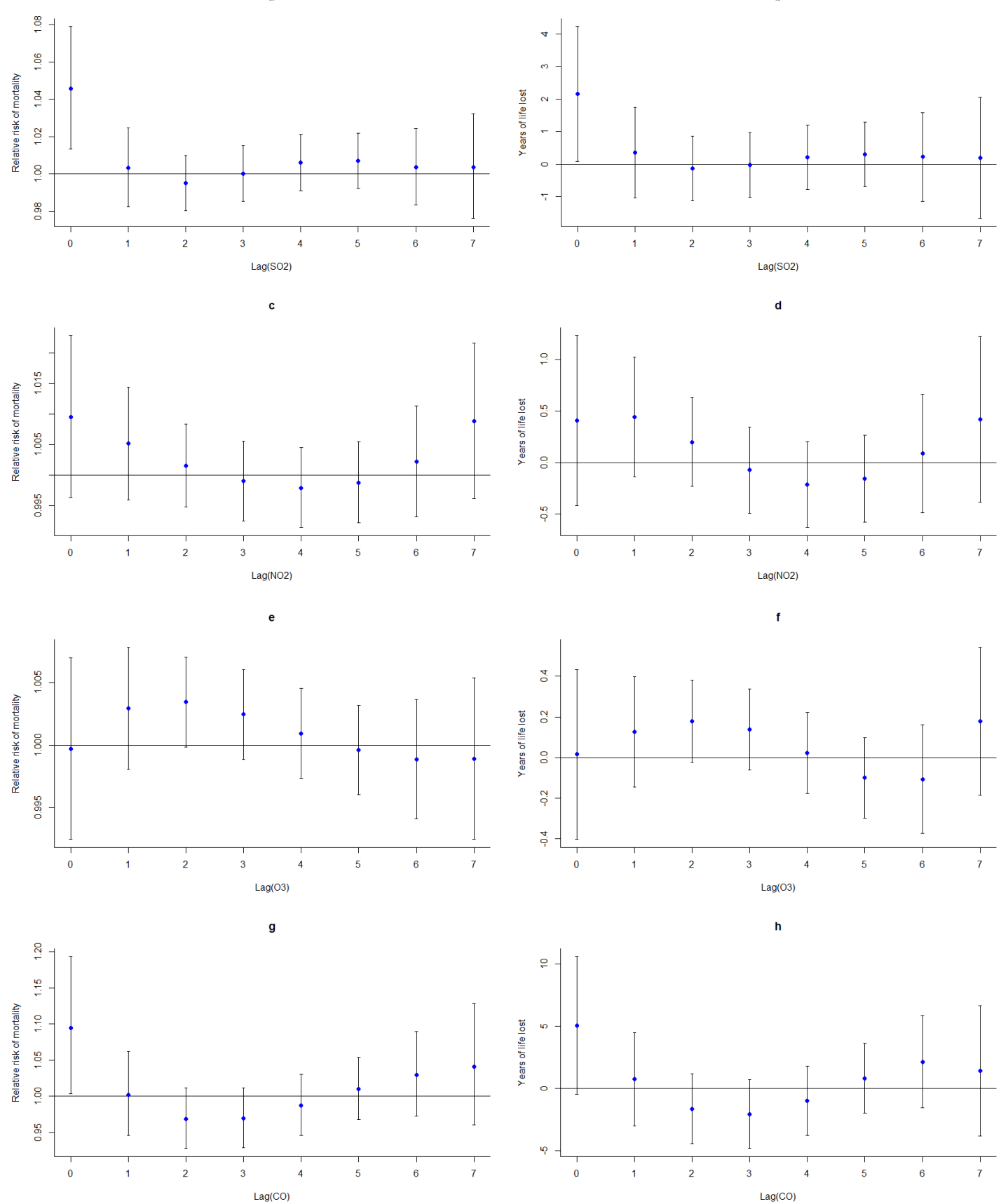

(a. Estimated changes in YLL associated with $\mathrm{SO}_{2}$; b. Relative risk of deaths associated with $\mathrm{SO}_{2}$; c. Estimated changes in $\mathrm{YLL}$ associated with $\mathrm{NO}_{2}$; d. Relative risk of deaths associated with $\mathrm{NO}_{2}$; e. Estimated changes in YLL associated with $\mathrm{O}_{3} ; \mathrm{f}$. Relative risk of deaths associated with $\mathrm{O}_{3}$; g. Estimated changes in YLL associated with CO; h. Relative risk of deaths associated with CO.) 
Table 3: Associations of $10 \mu \mathrm{g} / \mathrm{m} 3$ increase in $\mathrm{SO}_{2}, \mathrm{NO}_{2}, \mathrm{O}_{3}$ and $1 \mathrm{mg} / \mathrm{m}^{3}$ increase in CO daily COPD death counts and YLL.

\begin{tabular}{|c|c|c|c|c|c|c|c|}
\hline \multirow{2}{*}{$\begin{array}{l}\text { Outcome } \\
\text { and } \\
\text { Pollutant }\end{array}$} & \multicolumn{3}{|c|}{ Percentage increase in death $(95 \% \mathrm{Cl})$} & \multicolumn{4}{|c|}{ Increase of years of life lost $(95 \% \mathrm{Cl})$} \\
\hline & $\mathrm{SO}_{2}$ & $\mathrm{NO}_{2}$ & $\mathrm{CO}$ & $\mathrm{SO}_{2}$ & $\mathrm{NO}_{2}$ & $\mathrm{O}_{3}$ & $\mathrm{CO}$ \\
\hline lag0 day & $4.57(1.35,7.90)$ & $0.95(-0.36,2.28)$ & )$-0.03(-0.75,0.7) 9.46(0.40,19.35)$ & $2.16(0.09,4.23)$ & $0.41(-0.42,1.23)$ & $0.02(-0.40,0.43)$ & $5.05(-0.48,10.59)$ \\
\hline lag0-1 day & $4.93(1.47,8.50)$ & $1.47(0.14,2.82)$ & $0.26(-0.52,1.05) 9.68(-0.06,20.37)$ & $2.52(0.31,4.72)$ & $0.85(0.01,1.68)$ & $0.14(-0.31,0.59)$ & $5.78(-0.18,11.74)$ \\
\hline lag0-3 day & $4.40(0.48,8.48)$ & $1.52(-0.07,3.15)$ & $0.86(-0.06,1.78) 3.04(-8.28,15.75)$ & $2.38(-0.18,4.93)$ & $0.97(-0.03,1.98)$ & $0.46(-0.06,0.98)$ & $2.07(-5.38,9.52)$ \\
\hline lag0-5 day & $5.76(1.34,10.38)$ & ) $1.18(-0.64,3.04)$ & $0.91(-0.15,1.98) 2.73(-10.44,17.83)$ & $2.9(0.00,5.79)$ & $0.6(-0.57,1.77)$ & $0.38(-0.21,0.97)$ & $1.90(-6.94,10.74)$ \\
\hline lag0-7 day & $6.54(1.33,12.02)$ & $2.30(0.11,4.54)$ & $0.69(-0.55,1.94) 10.14(-6.58,29.85)$ & $3.32(-0.11,6.75)$ & $1.11(-0.29,2.51)$ & $0.45(-0.24,1.14)$ & $5.44(-5.22,16.1)$ \\
\hline
\end{tabular}

The results of the multiple pollutant models are listed in Table 4. For $\mathrm{SO}_{2}$, the estimates didn't change much, after the concentration of $\mathrm{NO}_{2}, \mathrm{O}_{3}$ and $\mathrm{CO}$ had been added into model. The estimate decreased and showed no statistical significance, after the concentration of $\mathrm{PM}_{10}$ had been included in the model. For $\mathrm{NO}_{2}$, the estimates were no longer statistically significant after controlling for $\mathrm{PM}_{10}, \mathrm{SO}_{2}$ and $\mathrm{CO}$, and the estimates were robust after the influence of $\mathrm{O}_{3}$ had been controlled for. For $\mathrm{O}_{3}$, after controlling for $\mathrm{PM}_{10}, \mathrm{SO}_{2}$, $\mathrm{NO}_{2}$ and $\mathrm{CO}$, the estimates remained stable, and were still not statistically significant. For $\mathrm{CO}$, after controlling for $\mathrm{PM}_{10}$ and $\mathrm{SO}_{2}$ the estimates decreased dramatically, and the estimates were stable after the concentration of $\mathrm{O}_{3}$ and $\mathrm{NO}_{2}$ had been added into model.

Table 4: Associations of $10 \mu \mathrm{g} / \mathrm{m} 3$ increase in $\mathrm{SO}_{2}, \mathrm{NO}_{2}, \mathrm{O}_{3}$ and $1 \mathrm{mg} / \mathrm{m} 3$ increase in CO (lag0-1day) daily COPD death counts and YLL using multi-pollutant model. 


\begin{tabular}{|c|c|c|}
\hline Pollutant and model & Percentage increase in death $(95 \% \mathrm{Cl})$ & Increase of years of life lost $(95 \% \mathrm{Cl})$ \\
\hline \multicolumn{3}{|l|}{$\mathrm{SO}_{2}$} \\
\hline Single-model & $4.93(1.47,8.50)$ & $2.52(0.31,4.72)$ \\
\hline$+\mathrm{PM}_{10}$ & $4.33(-0.40,9.27)$ & $1.70(-1.32,4.71)$ \\
\hline$+\mathrm{NO}_{2}$ & $5.91(1.42,10.59)$ & $2.61(-0.20,5.43)$ \\
\hline$+\mathrm{O}_{3}$ & $5.17(1.64,8.83)$ & $2.66(0.41,4.92)$ \\
\hline$+\mathrm{CO}$ & $6.49(1.71,11.48)$ & $3.04(0.09,6.00)$ \\
\hline \multicolumn{3}{|l|}{$\mathrm{NO}_{2}$} \\
\hline Single-model & $1.47(0.14,2.82)$ & $0.85(0.01,1.68)$ \\
\hline$+\mathrm{PM}_{10}$ & $0.35(-1.40,2.13)$ & $0.12(-1.01,1.25)$ \\
\hline$+\mathrm{SO}_{2}$ & $0.06(-1.86,2.02)$ & $0.28(-0.94,1.50)$ \\
\hline$+\mathrm{O}_{3}$ & $1.50(0.13,2.89)$ & $0.88(0.02,1.75)$ \\
\hline$+\mathrm{CO}$ & $0.75(-1.18,2.71)$ & $0.23(-0.99,1.45)$ \\
\hline \multicolumn{3}{|l|}{$\mathrm{O}_{3}$} \\
\hline Single-model & $0.26(-0.52,1.05)$ & $0.14(-0.31,0.59)$ \\
\hline$+\mathrm{PM}_{10}$ & $0.04(-0.76,0.85)$ & $-0.03(-0.50,0.44)$ \\
\hline$+\mathrm{SO}_{2}$ & $0.23(-0.58,1.04)$ & $0.10(-0.37,0.56)$ \\
\hline$+\mathrm{NO}_{2}$ & $0.31(-0.52,1.15)$ & $0.19(-0.29,0.68)$ \\
\hline$+\mathrm{CO}$ & $0.15(-0.66,0.97)$ & $-0.02(-0.49,0.45)$ \\
\hline \multicolumn{3}{|l|}{$\mathrm{CO}$} \\
\hline Single-model & $9.68(-0.06,20.37)$ & $5.78(-0.18,11.74)$ \\
\hline$+\mathrm{PM}_{10}$ & $-1.28(-15.22,14.95)$ & $-0.04(-9.48,9.40)$ \\
\hline$+\mathrm{SO}_{2}$ & $-2.24(-14.65,11.97)$ & $1.52(-7.03,10.07)$ \\
\hline$+\mathrm{NO}_{2}$ & $7.28(-6.20,22.69)$ & $4.98(-3.56,13.51)$ \\
\hline$+\mathrm{O}_{3}$ & $9.91(-0.11,20.93)$ & $6.05(-0.14,12.23)$ \\
\hline
\end{tabular}

The results of stratified analysis by age and education attainment are summarized in Table 5. Age stratification analysis showed that though the estimates of association in the elderly ( $\geq 80$ years) and younger population ( $<80$ years) were not statistically significantly different, we observed a trend that the estimates for association with $\mathrm{SO}_{2}$ and $\mathrm{NO}_{2}$ were stronger in the elderly ( $\geq 80$ years), and no significant effects were found on the younger 
population (<80 years). For different educational attainment levels, the effect estimates of $\mathrm{SO}_{2}$ and $\mathrm{CO}$ in the lower educated population on YLL due to COPD death were significantly stronger than that in the higher educated population. There was a trend that the effect estimates of gaseous air pollution $\left(\mathrm{SO}_{2}, \mathrm{NO}_{2}\right.$ and $\left.\mathrm{CO}\right)$ on daily COPD death count and $\mathrm{NO}_{2}$ on $\mathrm{YLL}$ in the lower educated population were stronger than that in the higher educated population, though the difference was not significant. The effect estimates of gaseous air pollution $\left(\mathrm{SO}_{2}, \mathrm{NO}_{2}\right.$ and $\left.\mathrm{CO}\right)$ in the higher educated population were not statistically significant, both on daily COPD death count and YLL due to COPD.

Table 5: Associations of $\mathrm{SO}_{2}, \mathrm{NO}_{2}$ and $\mathrm{CO}$ with daily COPD death counts and YLL stratified by age, and education attainment.

\begin{tabular}{|c|c|c|c|c|c|c|}
\hline \multirow{2}{*}{$\begin{array}{l}\text { Outcome and } \\
\text { Pollutant }\end{array}$} & \multicolumn{3}{|c|}{ Percentage increase in death $(95 \% \mathrm{Cl})$} & \multicolumn{3}{|c|}{ Increase of years of life lost $(95 \% \mathrm{Cl})$} \\
\hline & $\mathrm{SO}_{2}$ & $\mathrm{NO}_{2}$ & $\mathrm{CO}$ & $\mathrm{SO}_{2}$ & $\mathrm{NO}_{2}$ & $\mathrm{CO}$ \\
\hline \multicolumn{7}{|c|}{ Lower educated population } \\
\hline lag0 day & $5.53(1.65,9.57)$ & $0.77(-0.8,2.36)$ & $10.27(-0.58,22.30)$ & $2.78(1.20,4.35)^{*}$ & $0.24(-0.39,0.87)$ & $5.25(1.03,9.48)$ \\
\hline ag0-1 day & $6.14(1.99,10.46)$ & $1.64(0.05,3.26)$ & $10.85(-0.84,23.92)$ & $3.21(1.53,4.89)^{*}$ & $0.77(0.13,1.40)$ & $6.21(1.66,10.76)^{*}$ \\
\hline lag0-3 day & $4.71(0.04,9.59)$ & $1.22(-0.68,3.15)$ & $1.67(-11.53,16.84)$ & $2.43(0.49,4.38)$ & $0.63(-0.14,1.40)$ & $2.16(-3.53,7.84)$ \\
\hline ag0-5 day & $6.87(1.59,12.43)$ & $0.93(-1.23,3.14)$ & $0.67(-14.55,18.61)$ & $3.08(0.88,5.29)^{*}$ & $0.36(-0.53,1.25)$ & $1.11(-5.63,7.86)$ \\
\hline ag0-7 day & $7.43(1.23,14.02)$ & $2.24(-0.37,4.91)$ & $8.30(-11.01,31.80)$ & $3.34(0.72,5.95)$ & $0.77(-0.30,1.84)$ & $3.38(-4.75,11.52)$ \\
\hline \multicolumn{7}{|c|}{ Higher educated population } \\
\hline lag0 day & $2.48(-3.22,8.52)$ & $1.37(-1.03,3.83)$ & $7.88(-7.80,26.24)$ & $-0.62(-1.95,0.70)$ & $0.16(-0.36,0.69)$ & $-0.20(-3.74,3.35)$ \\
\hline lag0-1 day & $2.15(-3.98,8.67)$ & $1.09(-1.31,3.56)$ & $7.36(-9.32,27.11)$ & $-0.69(-2.10,0.72)$ & $0.08(-0.45,0.62)$ & $-0.43(-4.25,3.38)$ \\
\hline lag0-3 day & $3.59(-3.51,11.22)$ & $2.29(-0.65,5.31)$ & $6.56(-13.87,31.83)$ & $-0.05(-1.69,1.58)$ & $0.34(-0.30,0.99)$ & $-0.09(-4.86,4.68)$ \\
\hline ag0-5 day & $3.11(-4.75,11.61)$ & $1.82(-1.53,5.29)$ & $7.89(-16.05,38.65)$ & $-0.19(-2.04,1.67)$ & $0.24(-0.51,0.98)$ & $0.79(-4.87,6.44)$ \\
\hline ag0-7 day & $4.31(-5.00,14.53)$ & $2.48(-1.53,6.67)$ & $14.91(-15.05,55.46)$ & $-0.02(-2.21,2.17)$ & $0.34(-0.55,1.24)$ & $2.05(-4.77,8.88)$ \\
\hline
\end{tabular}




\begin{tabular}{lllllll} 
lag0 day & $1.78(-4.32,8.26)$ & $0.26(-2.30,2.90)$ & $8.79(-8.30,29.06)$ & $0.13(-1.49,1.76)$ & $0.01(-0.64,0.66)$ & $1.85(-2.49,6.19)$ \\
lag0-1 day & $2.76(-3.81,9.79)$ & $1.47(-1.14,4.16)$ & $14.00(-5.13,36.99)$ & $0.39(-1.33,2.12)$ & $0.33(-0.32,0.99)$ & $2.71(-1.96,7.38)$ \\
lag0-3 day & $1.77(-5.70,9.83)$ & $2.34(-0.80,5.58)$ & $7.74(-14.25,35.37)$ & $0.51(-1.49,2.52)$ & $0.61(-0.18,1.40)$ & $1.73(-4.11,7.57)$ \\
lag0-5 day & $0.31(-7.89,9.24)$ & $0.67(-2.88,4.36)$ & $2.98(-21.37,34.87)$ & $0.16(-2.11,2.43)$ & $0.21(-0.71,1.12)$ & $1.35(-5.58,8.28)$ \\
lag0-7 day & $1.67(-7.99,12.34)$ & $1.05(-3.19,5.48)$ & $12.88(-18.19,55.75)$ & $0.32(-2.37,3.01)$ & $0.23(-0.87,1.33)$ & $2.61(-5.74,10.96)$ \\
Age $\geq 80$ years & & & & & & \\
lag0 day & $5.59(1.81,9.50)$ & $1.20(-0.33,2.75)$ & $9.78(-0.69,21.36)$ & $2.02(0.78,3.27)$ & $0.40(-0.10,0.89)$ & $3.21(-0.13,6.54)$ \\
lag0-1 day & $5.74(1.71,9.93)$ & $1.49(-0.06,3.05)$ & $8.41(-2.67,20.76)$ & $2.12(0.80,3.45)$ & $0.51(0.01,1.02)$ & $3.07(-0.52,6.66)$ \\
lag0-3 day & $5.36(0.79,10.14)$ & $1.26(-0.59,3.14)$ & $1.61(-11.25,16.34)$ & $1.87(0.33,3.40)$ & $0.36(-0.24,0.97)$ & $0.34(-4.15,4.82)$ \\
lag0-5 day & $7.78(2.59,13.23)$ & $1.37(-0.75,3.53)$ & $2.68(-12.45,20.43)$ & $2.74(1.00,4.48)$ & $0.39(-0.31,1.10)$ & $0.55(-4.77,5.87)$ \\
lag0-7 day & $8.32(2.21,14.81)$ & $2.75(0.20,5.37)$ & $9.34(-9.73,32.43)$ & $3.00(0.94,5.06)$ & $0.88(0.04,1.72)$ & $2.83(-3.59,9.24)$ \\
\hline
\end{tabular}

Note:Associations with $10 \mu \mathrm{g} / \mathrm{m} 3$ increase in SO2, NO2 and $1 \mathrm{mg} / \mathrm{m} 3$ in CO . Data were collected from PNA, China, 2013-2019. ${ }^{*} P<0.05$

\section{Discussion}

The relationship between ambient gaseous air pollutants and an excess mortality risk have been well documented. A number of previous studies have examined the relationship between air pollution and COPD mortality in several cities. Discrepancies in the results were found among these studies that indicate the existence of regional variations[25-27]. Most of these studies take the daily death count as the indicator for examining the impact of air pollution, ignoring the difference in the age at which the death occurred. From a public health perspective, deaths that happen at different ages is not of equal importance, as the deaths occurring in a younger age group would lead to increased YLL. However, studies taking YLL as an indicator in exploring the impact on COPD deaths in China were still rare, with only two studies performed in Ningbo, to our knowledge, that had used YLL in exploring the 
impact of $\mathrm{PM}_{2.5}$ and $\mathrm{O}_{3}$ on COPD death $[28,29]$.

Our study for the first time explored the relationship between the short-term exposure to gaseous air pollution including $\mathrm{SO}_{2}, \mathrm{NO}_{2}, \mathrm{O}_{3}$ and $\mathrm{CO}$ with daily YLL caused by COPD. This analysis, based on the data of 12,781 COPD deaths over the seven years from 2013 to 2019, confirmed that exposure to $\mathrm{SO}_{2}, \mathrm{NO}_{2}$, and $\mathrm{CO}$ was positively associated with mortality and YLL due to COPD in PNA, China. We also determined that the effect of $\mathrm{O}_{3}$ was not significant. Our findings regarding $\mathrm{SO}_{2}$ and $\mathrm{NO}_{2}$ were in agreement with the studies performed in several Chinese metropolises located in different regions of China $[26,27,30]$. We found that the effect of $\mathrm{O}_{3}$ on YLL due to COPD was different from the finding in Ningbo, also located in the Yangtze River Delta Region. The results from the Ningbo study showed that a rise in $\mathrm{O}_{3}$ concentration would increase the YLL due to COPD significantly [28]. This indicates that the associations differ by the location of the studies. Thus, more investigations should be conducted to explore the impact of air pollutants on YLL due to COPD, especially the impact of $\mathrm{O}_{3}$.

In our study, we found that compared with the impact of $\mathrm{NO}_{2}, \mathrm{SO}_{2}$ poses more influence on YLL and a heavier disease burden from COPD for its higher relative risk (RR), though the concentration of $\mathrm{SO}_{2}$ was lower. This result was opposite to that of a systematic review covering 80 major cities in China [31], which reported that the pooled $\mathrm{RR}$ of $\mathrm{NO}_{2}$ was higher than that of $\mathrm{SO}_{2}$. The difference might be attributed to the diversity in the concentration of 
air pollutants. The Integrated Emission Standard of Air Pollutants, introduced by the Shanghai municipal government in 2015 , resulted in the concentration of $\mathrm{SO}_{2}$ in Shanghai to be reduced significantly, reaching a relatively low level for China. Several existing studies have proved that the exposure-response curve of air pollutants to COPD was steep even at a low level of pollution. This indicates that more measures should be taken to control air pollution even when it is still at a relatively low level[26, 27, 32].

In our study, we found a trend that the impact of gaseous air pollution on both YLL and the daily death count was stronger among the elderly ( $\geq 80$ years), and that the impact among younger people (<80 years) was not significant. Our study further confirmed that the elderly are the vulnerable subgroup to gaseous air pollution, and from the biological perspective, this observation was plausible. Both lung and immunologic function are gradually reduced with aging, which can lead to a decrease of the physiologic reserve for coping with the hazards of air pollution [33, 34]. Furthermore, the higher morbidity of pre-existing chronic disease among the elderly also decreases the resistance to air pollution's negative effects[35, 36]. This result was consistent with the previous studies performed in Ningbo and Wuxi [23, 24], but was different from the study conducted in Beijing that reported that the impact of $\mathrm{SO}_{2}$ and $\mathrm{NO}_{2}$ on $\mathrm{YLL}$ was higher among the younger population[37]. The regional difference may result from the different levels of gaseous air pollution among regions. In Beijing the mean concentration of $\mathrm{SO}_{2}$ and $\mathrm{NO}_{2}$ 
were $48.6 \mu \mathrm{g} / \mathrm{m}^{3}$ and $64.2 \mu \mathrm{g} / \mathrm{m}^{3}$, respectively, which was much lower than that of Shanghai, Ningbo and Wuxi.

After stratification by educational attainment, we found the YLL due to COPD among the lower educated population was more susceptible to $\mathrm{SO}_{2}$ $\mathrm{NO}_{2}$ and $\mathrm{CO}$ exposure. This indicates that the excess death due to COPD among the low educated population triggered by ambient $\mathrm{SO}_{2}$ and $\mathrm{NO}_{2}$ happened at a relatively low age. We considered that this could be explained by three aspects: First, the low educated population usually suffered from economic crisis that limited their ability to achieve better living conditions and access to high-quality medical care $[38,39]$. In addition, the lower economic condition and the lack of hygienic knowledge limited the low educated population's ability to obtain fresh and nutritious food. This dietary restriction has been proved to increase the risk of COPD [40-42]. Finally, manual labor, usually undertaken by the low educated population, leads them to experience more exposure to outdoor air pollution $[43,44]$.

This study has several strengths. First, our study is the first done in China to explore the impact of gaseous air pollutants on YLL due to COPD. The use of YLL as the key indicator in the measurement of the association between air pollution and premature deaths could provide a more accurate and straightforward reference for policy-making and resource allocation than that of a daily death count. Second, as one of the economic development zones in China, PNA could be regarded as a microcosm of the rapidly developing 
regions in Eastern China. Our findings could partially represent the situation in other similar regions such as Shenzhen City and Tianjin Binhai New Area due to their similar socio-economic conditions and geographic location.

The limitations of our study also should be noted. First, the average concentrations of air pollutants we used to assess the population exposure condition derived from the nine comprehensive monitoring stations located in Shanghai, and measurement error may exist. Second, due to the limitations of death surveillance, the individual pre-existing health conditions, and that the behavioral risk factors such as smoking and drinking remain unknown, are uncontrolled for in the present study. Third, the YLL, in our study, was accessed on the basis of the local life expectancy of PNA general residents. Thus, the impact of air pollutants could be overestimated. Fourth, our finding was based on the data from PNA, however, the socio-economic status and distribution of the air pollutants might vary across different cities. Thus, cautions should be taken in the generalization of these results.

\section{Conclusions}

In conclusion, we found that $\mathrm{SO}_{2}, \mathrm{NO}_{2}$ and $\mathrm{CO}$ had significant impacts on both daily death counts and YLL due to COPD in PNA, China. The association with $\mathrm{SO}_{2}$ was relatively stronger than that with $\mathrm{NO}_{2}$. The elderly and lower educated population were more susceptible to the hazards of 
gaseous air pollution including $\mathrm{SO}_{2}, \mathrm{NO}_{2}$ and $\mathrm{CO}$. Thus, the impact of gaseous air pollution was stronger among those aged $\geq 80$ years. These results, in line with previous studies, indicate that stricter standards for exhaust emissions should be set and implemented in China, and more attention should be paid to the vulnerable subgroups.

\section{Additional file}

\section{Additional file 1:}

Table S1. Life expectancy for Pudong New Area population, 2013-2019.

\section{Abbreviations}

$\mathrm{Cl}$ : Confidence interval; CO: Carbon monoxide; COPD: Chronic obstructive pulmonary disease; DLNM: Distributed lag nonlinear model; RR: Relative Risk; $\mathrm{NO}_{2}$ : Nitrogen dioxide; $\mathrm{O}_{3}$ : Ozone; PNA: Pudong New Area, $\mathrm{SO}_{2}$ : Sulfur dioxide; WHO: World Health Organization; YLL: Years of life lost.

\section{Acknowledgement}

We thank the Shanghai Key Laboratory of Meteorology and Health and the Shanghai Environmental Monitoring Center for providing the meteorological data and air pollution data, respectively. We also thank all the vital statistic participants of Pudong New Area from 2013 to 2019, for their great work in the collection of the COPD mortality data.

\section{Funding}

This study was supported by a grant from the Open Fund of the Shanghai 
Key Laboratory of Meteorology and Health (No. QXJK201804 to YC), the Fund for Academic Leader Training Program of the Health Commission of Pudong New Area (No.PWRd2019-11 to YZ), the Fund of National Key R\&D Program of China (No.2017YFC09070000 to GZ), the Fund for the Young Medical Talents Training Program of Shanghai Municipal Health Commission (No.GWV-10.2-YQ43 to YC). The funder had no role in the study design, data collection and analysis, decision to publish, or preparation of the manuscript.

\section{Availability of data and material}

Raw data for COPD mortality used in this study was obtained from the Center for Disease Control and Prevention of the Pudong New Area, Shanghai. The raw data for meteorology and daily air pollution concentrations were requested from the Shanghai Key Laboratory of Meteorology and Health and the Shanghai Environmental Monitoring Center, respectively. The de-identified data analyzed in the current study could be available from the corresponding author in the manuscript with the permission of Shanghai Pudong New area Center for Disease Control and Prevention.

\section{Author's contributions}

$\mathrm{YC}$ and $\mathrm{XL}$ conducted the statistical analyses and wrote the manuscript together. The two authors are responsible for the accuracy of the analysis and contributed equally to this study. HC and LS contributed to the COPD mortality data collection and took responsibility for the integrity of this data. TL and SX gave the advice for the design of this study and participated in the coordination during the study period. MY and GZ conducted the literature review and gave suggestions for analysis. LP directed the implementation and reviewed the manuscript. YZ conceived of the study, and participated in the development of 
this work. All authors read and approved the final manuscript.

\section{Competing interests}

The authors declare that they have no competing interests.

\section{Consent for publication}

Not applicable

\section{Ethics approval and consent to participate}

The study was approved by Ethics Committee of Shanghai Pudong New Area Center for Disease Control and Prevention, Shanghai, P. R. China. The administrative permission for the using of the death surveillance data was jointly granted by the Ministry of public security, Health Commission and Ministry of Civil Affairs, PRC. The present study was a retrospective research, and Ethics Committee of Shanghai Pudong New Area Center for Disease Control and Prevention had ruled that no formal consent was necessary. Individual information was de-identified and anonymized prior to analysis. Strict confidentiality of individual data was practiced during the entire study. 


\section{References}

[1] Liu W, Xu Z, Yang T. Health Effects of Air Pollution in China. Int J Environ Res Public Health. 2018; 15(7):1471.

[2] The Lancet. Air pollution: a major threat to lung health. Lancet. 2019; 393(10183):1774.

[3] Yao L, Zhan B, Xian A, et al. Contribution of transregional transport to particle pollution and health effects in Shanghai during 2013-2017. Sci Total Environ. 2019; 677:564-570.

[4] Mo Z, Fu Q, Zhang L, et al. Acute effects of air pollution on respiratory disease mortalities and outpatients in Southeastern China. Sci Rep. 2018; 8(1):3461.

[5] Lee D, Robertson C, Ramsay C, et al. Estimating the health impact of air pollution in Scotland, and the resulting benefits of reducing concentrations in city centres. Spat Spatiotemporal Epidemiol, 2019; 29:85-96.

[6] Ren M, Li N, Wang Z, et al. The short-term effects of air pollutants on respiratory disease mortality in Wuhan, China: comparison of time-series and case-crossover analyses. Sci Rep. 2017; 7:40482.

[7] Zhao L, Liang H, Chen F, et al. Association between air pollution and cardiovascular mortality in China: a systematic review and meta-analysis. Oncotarget. 2017;8(39):66438-66448.

[8] Huang F, Luo Y, Tan P, et al., Gaseous Air Pollution and the Risk for Stroke Admissions: A Case-Crossover Study in Beijing, China. Int J Environ Res Public Health. 2017; 14(2):189.

[9] Li D, Wang JB, Zhang ZY, et al. Association between short-term exposure to ambient air pollution and daily mortality: a time-series study in Eastern China. Environ Sci Pollut Res Int. Environ Sci Pollut Res Int. 2018;25(16):16135-43.

[10] Chen R, Yin P, Meng X, et al. Fine Particulate Air Pollution and Daily Mortality. A Nationwide Analysis in 272 Chinese Cities. Am J Respir Crit Care Med. 2017;196(1):73-81.

[11] Liu Y, Chen S, Xu J, et al. The Association between Air Pollution and Outpatient and Inpatient Visits in Shenzhen, China. Int J Environ Res Public Health. 2018;15(2):178.

[12] Thun MJ, DeLancey JO, Center MM, et al. The global burden of cancer: priorities for prevention. Carcinogenesis. 2010;31(1):100-10.

[13] Brustugun OT, Møller B, Helland A. Helland, Years of life lost as a measure of cancer burden on a national level. Br J Cancer. Br J Cancer. 2014;111(5):1014-20

[14] Singh D, Agusti A, Anzueto A, et al. Global Strategy for the Diagnosis, Management, and Prevention of Chronic Obstructive Lung Disease: the GOLD science committee report 2019. Eur Respir J. 2019;53(5):1900164.

[15] Huang X, Fu W, Zhang H, et al. Why are male Chinese smokers unwilling to quit? A multicentre cross-sectional study on smoking rationalisation and intention to quit. BMJ Open. 2019; 9(2):e025285.

[16] GBD 2017 Causes of Death Collaborators. Global, regional, and national age-sex-specific mortality for 282 causes of death in 195 countries and territories, 1980-2017: a systematic analysis for the Global Burden of Disease Study 2017. Lancet. 2018; 392(10159):1736-1788.

[17] Li L, Yang J, Song YF, et al. The burden of COPD mortality due to ambient air pollution in Guangzhou, China. Sci Rep. 2016;6:25900.

[18] Chen H, Hao L, Yang C, et al. Understanding the rapid increase in life expectancy in shanghai, China: a population-based retrospective analysis. BMC Public Health. 2018; 18(1):256.

[19] Xiao T, Qiu H, Chen Y, et al., Prevalence of anxiety and depression symptoms and their associated factors in mild COPD patients from community settings, Shanghai, China: a cross-sectional study. 
BMC Psychiatry. 2018; 18(1):89.

[20] Wang Z, Peng J, Liu P, et al. Association between short-term exposure to air pollution and ischemic stroke onset: a time-stratified case-crossover analysis using a distributed lag nonlinear model in Shenzhen, China. Environ Health, Environ Health. 2020;19(1):1.

[21] Armstrong BG, Gasparrini A, Tobias A. Conditional Poisson models: a flexible alternative to conditional logistic case cross-over analysis. BMC Med Res Methodol. 2014;14:122.

[22] Gasparrini A. Modeling exposure-lag-response associations with distributed lag non-linear models. Statistics in Medicine. 2014. 33(5): 881-899.

[23] He T, Yang Z, Liu T, et al. Ambient air pollution and years of life lost in Ningbo, China. Sci Rep. Sci Rep. 2016;6:22485.

[24] Zhu J, Zhang X, Zhang X, et al., The burden of ambient air pollution on years of life lost in Wuxi, China, 2012-2015: A time-series study using a distributed lag non-linear model. Environ Pollut. 2017; 224:689-697.

[25] Chen R, Yin P, Meng X, et al., Associations between Coarse Particulate Matter Air Pollution and Cause-Specific Mortality: A Nationwide Analysis in 272 Chinese Cities. Environ Health Perspect. 2019; 127(1):17008.

[26] Wang L, Liu C, Meng X, et al. Associations between short-term exposure to ambient sulfur dioxide and increased cause-specific mortality in 272 Chinese cities. Environ Int. 2018;117:33-39.

[27] Chen R, Yin P, Meng X, et al. Associations Between Ambient Nitrogen Dioxide and Daily Cause-specific Mortality. Epidemiology. 2018; 29(4):482-489.

[28] Huang J, Li G, Xu G, et al. The burden of ozone pollution on years of life lost from chronic obstructive pulmonary disease in a city of Yangtze River Delta, China. Environ Pollut. 2018;242(Pt B):1266-1273.

[29] Li G, Huang J, Xu G, et al. The short term burden of ambient fine particulate matter on chronic obstructive pulmonary disease in Ningbo, China. Environ Health. 2017;16(1):54.

[30] Mokoena KK, Ethan CJ, Yu Y, et al. Ambient air pollution and respiratory mortality in Xi'an, China: a time-series analysis. Respir Res. 2019; 20(1):139.

[31] Lai HK, Tsang H, Wong CM. Meta-analysis of adverse health effects due to air pollution in Chinese populations. BMC Public Health. 2013;13:360.

[32] Ghozikali MG, Mosaferi M, Safari GH, et al., Effect of exposure to $\mathrm{O}_{3}, \mathrm{NO}_{2}$, and $\mathrm{SO}_{2}$ on chronic obstructive pulmonary disease hospitalizations in Tabriz, Iran. Environ Sci Pollut Res Int. 2015; 22(4):2817-23.

[33] Vaz Fragoso CA, Gill TM. Respiratory impairment and the aging lung: a novel paradigm for assessing pulmonary function. J Gerontol A Biol Sci Med Sci. 2012;67(3):264-75.

[34] Boe DM, Boule LA, Kovacs EJ. Innate immune responses in the ageing lung. Clin Exp Immunol. 2017;187(1):16-25.

[35] Faustini A, Stafoggia M, Cappai G, et al. Short-term effects of air pollution in a cohort of patients with chronic obstructive pulmonary disease. Epidemiology. 2012;23(6):861-79.

[36] Goldberg MS, Burnett RT, Stieb DM, et al. Associations between ambient air pollution and daily mortality among elderly persons in Montreal, Quebec. Sci Total Environ. 2013;463-464:931-42.

[37] Guo Y, Li S, Tian Z, et al. The burden of air pollution on years of life lost in Beijing, China, 2004-08: retrospective regression analysis of daily deaths. BMJ. 2013; 347:f7139.

[38] Emilio CC, Mingotti CFB, Fiorin PR, et al. Is a low level of education a limiting factor for asthma control in a population with access to pulmonologists and to treatment? J Bras Pneumol. 2019; 
45(1):e20180052.

[39] Cambois E, Solé-Auró A, Robine JM. Robine, Economic Hardship and Educational Differentials in Disability in 26 European Countries. J Aging Health. 2016; 28(7):1214-38.

[40] Shaheen SO, Jameson KA, Syddall HE, et al. The relationship of dietary patterns with adult lung function and COPD. Eur Respir J. 2010;36(2):277-84.

[41] Cornell K, Alam M, Lyden E, et al. Saturated Fat Intake Is Associated with Lung Function in Individuals with Airflow Obstruction: Results from NHANES 2007 $\square$ 2012.Nutrients. 2019; 11(2):317.

[42] Varraso R, Chiuve SE, Fung TT, et al., Alternate Healthy Eating Index 2010 and risk of chronic obstructive pulmonary disease among US women and men: prospective study. BMJ. 2015;350:h286.

[43] Ou CQ, Hedley AJ, Chung RY, et al. Socioeconomic disparities in air pollution-associated mortality. Environ Res. 2008; 107(2):237-44.

[44] Jerrett M, Burnett RT, Brook J, et al. Do socioeconomic characteristics modify the short term association between air pollution and mortality? Evidence from a zonal time series in Hamilton, Canada. J Epidemiol Community Health. 2004;58(1):31-40. 


\section{Figures}

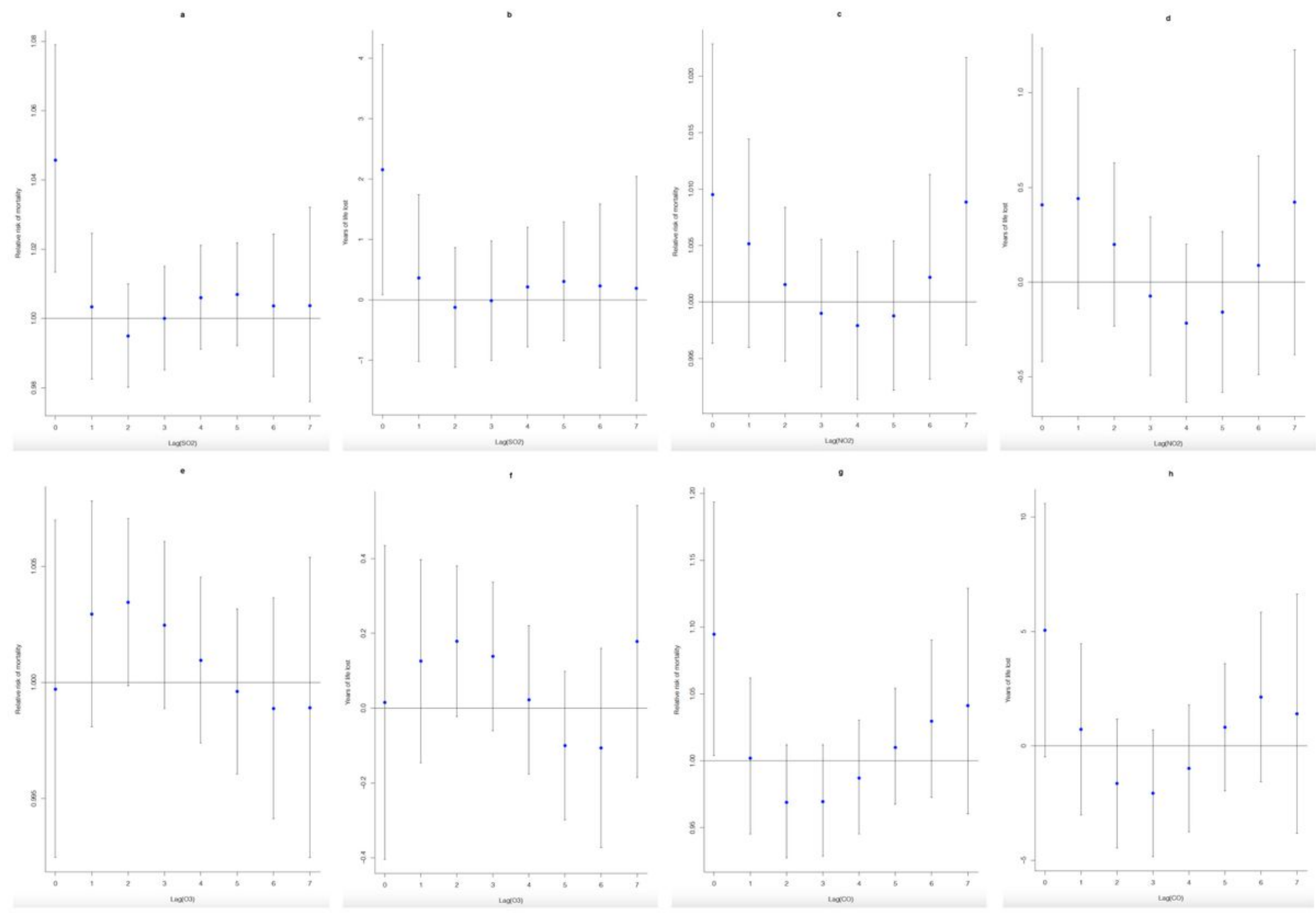

\section{Figure 1}

The estimated changes with a 95\% confidence interval in daily COPD death counts and YLL associated with $10 \mu \mathrm{g} / \mathrm{m} 3$ increase in SO2, NO2, O3, and $1 \mathrm{mg} / \mathrm{m} 3$ increase in CO in different lag days in PNA, China, 2013-2019. The effects of seasonality, day of the week, and meteorological factors have been adjusted. (a. Estimated changes in YLL associated with SO2; b. Relative risk of deaths associated with SO2; c. Estimated changes in YLL associated with NO2; d. Relative risk of deaths associated with NO2; e. Estimated changes in YLL associated with 03; f. Relative risk of deaths associated with 03; g. Estimated changes in YLL associated with CO; h. Relative risk of deaths associated with CO.)

\section{Supplementary Files}

This is a list of supplementary files associated with this preprint. Click to download.

- TableS1.xlsx 